\title{
Hypocenter and focal mechanism distributions of aftershocks of July 262003 M6.4 northern Miyagi, NE Japan, earthquake revealed by temporary seismic observation
}

\author{
Norihito Umino ${ }^{1}$, Tomomi Okada ${ }^{1}$, Junichi Nakajima ${ }^{1}$, Shuichiro Hori ${ }^{1}$, Toshio Kono ${ }^{1}$, Takashi Nakayama ${ }^{1}$, Naoki Uchida $^{1}$, \\ Junpei Shimizu ${ }^{1}$, Junichi Suganomata ${ }^{1}$, Shantha S. N. Gamage ${ }^{1}$, Akira Hasegawa ${ }^{1}$, and Youichi Asano ${ }^{2}$ \\ ${ }^{1}$ Research Center for Prediction of Earthquakes and Volcanic Eruptions, Graduate School of Science, Tohoku University, Aramaki Aza Aoba, \\ Aoba-ku, Sendai, Miyagi 980-8578, Japan \\ ${ }^{2}$ National Research Institute for Earth Science and Disaster Prevention, Tennoudai 3-1, Tsukuba, Ibaraki 305-0006, Japan
}

(Received October 22, 2003; Revised December 29, 2003; Accepted December 29, 2003)

\begin{abstract}
We conducted a temporary seismic observation just after the occurrence of July 26, 2003, M6.4 northern Miyagi earthquake, in order to precisely locate aftershock hypocenters. Thirteen portable data-logger stations and one satellite communication telemetry station were installed in and around the focal area of the M6.4 event. Hypocenters of aftershocks were located by using data observed at those temporary stations and nearby permanent stations of Tohoku University, National Research Institute for Earth Science and Disaster Prevention (NIED) and Japan Meteorological Agency (JMA). Obtained aftershock distribution clearly delineates the fault plane of this M6.4 event in the depth range of 3-12 km. The fault plane dips westward at an angle of $\sim 50$ degree in the northern part of the aftershock area and northwestward at $\sim 40$ degree in the southern part. Data observed at dense temporary stations just above the focal area and nearby permanent stations allowed us to determine focal mechanisms of many aftershocks. The results show that focal mechanism of reverse fault type is predominant in this aftershock sequence. Directions of $P$-axes, however, varies mainly with locations of hypocenters, and are classified into three groups. Aftershocks with $P$-axis of NW-SE direction occurred mainly in the southern part of the aftershock area where the M5.6 foreshock and the main shock ruptures were initiated. Many aftershocks with $P$-axis of east-west direction took place in the central part of the aftershock area where large amount of fault slips by the main shock were estimated from waveform inversions. Many aftershocks in the northernmost part of the aftershock area have focal mechanisms with $P$-axis of NE-SW direction, similar to that of the M5.5 largest aftershock. A few aftershocks with normal fault type occurred close to convex regions of the main shock fault plane or outside of it.
\end{abstract}

Key words: Northern Miyagi earthquake, shallow earthquake, aftershock, earthquake fault, focal mechanism, northeastern Japan arc.

\section{Introduction}

An M6.4 shallow earthquake occurred in the northern Miyagi Prefecture, northeastern Japan, on 07:13 July 26, 2003. This earthquake was accompanied with a distinct foreshock activity. The largest foreshock (M5.6) took place about $3 \mathrm{~km}$ north from the epicenter of the main shock on 00:13 July 26. Okada et al. (2003) estimated locations of the largest foreshock (M5.6), the main shock and the largest aftershock (M5.5) from a double deference hypocenter locations algorithm (Waldhauser and Ellsworth, 2001) and determined their focal mechanisms by using $P$-wave polarities (Horiuchi et al., 1972) observed at permanent seismic stations of Tohoku University, NIED and JMA.

Since no seismic stations had been installed within a 15 $\mathrm{km}$ radius from the epicenter of the main shock (shown by an open star $\mathrm{M}$ in Fig. 1), hypocenters, particularly focal depths, of this earthquake sequence wouldn't be determined precisely by those seismic networks. In order to estimate precise locations and focal mechanisms of aftershocks, we

Copy right(C) The Society of Geomagnetism and Earth, Planetary and Space Sciences (SGEPSS); The Seismological Society of Japan; The Volcanological Society of Japan; The Geodetic Society of Japan; The Japanese Society for Planetary Sciences. constructed a temporary seismic network with portable datalogger stations and a satellite communication telemetry station in and around the focal area of this sequence (Umino et al., 2003). Thirteen stations with data-loggers started observations just after the occurrence of the largest aftershock (M5.5) on 16:56 July 26. Signals of 3 components of $2 \mathrm{~Hz}$ seismographs are continuously recorded at $100 \mathrm{~Hz}$ sampling rate on data-logger (LS7000; Hakusan Co.). Locations of the data-logger stations are shown by solid squares in Fig. 1. Moreover, a satellite communication telemetry station, shown by a plus in Fig. 1, was installed just above the largest foreshock on July 28.

\section{Hypocenter distribution}

Hypocenters of aftershocks were estimated from a single event locations method (Hasegawa et al., 1978) by using data observed at those temporary stations and nearby permanent stations of Tohoku University (shown by circles in Fig. 1), NIED (shown by reverse triangles in Fig. 1) and JMA (shown by triangles in Fig. 1), based on $P$ - and $S$-wave velocity model adopted in the routine procedure of Tohoku University seismic network (Hasegawa et al., 1978). 


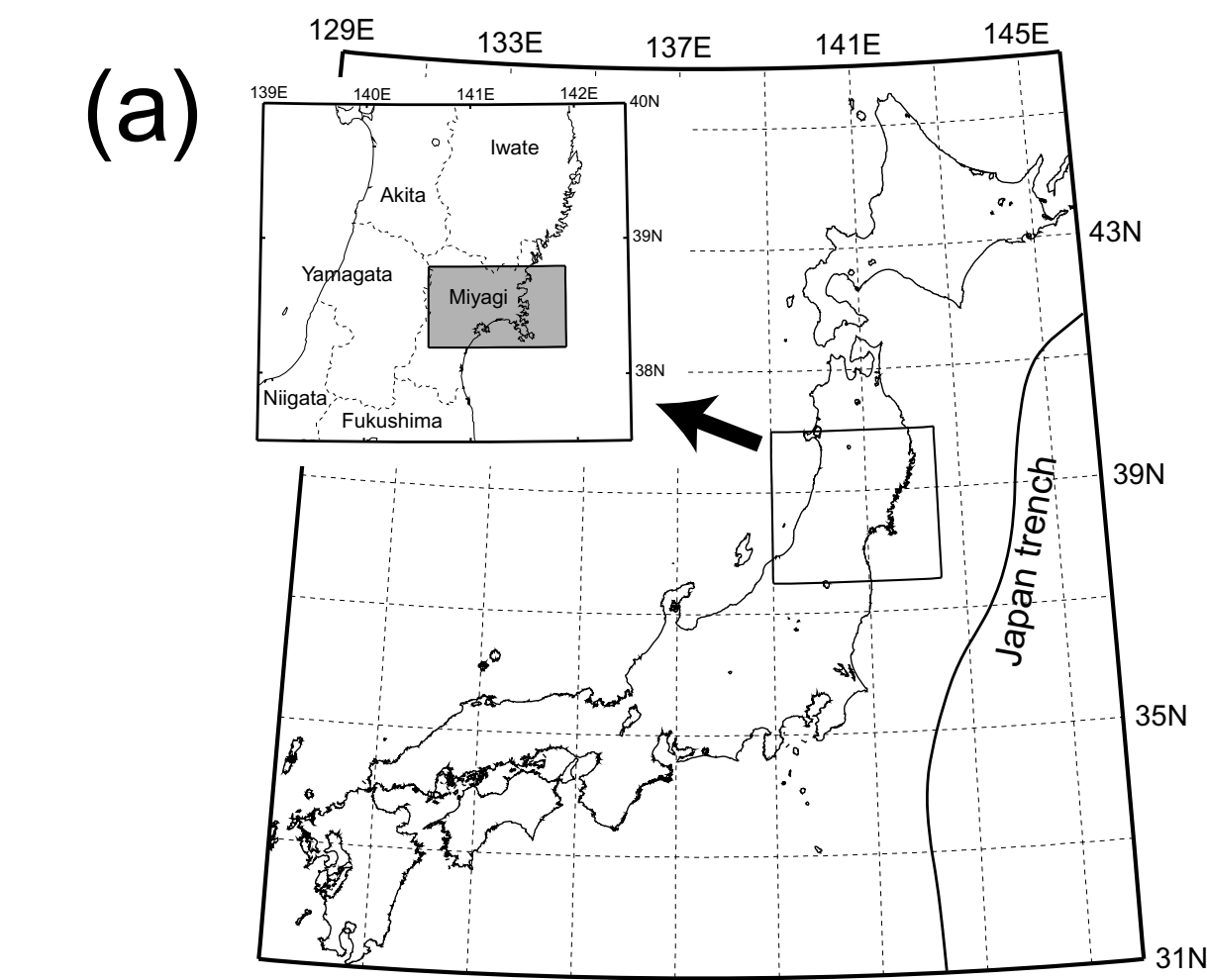

(b)

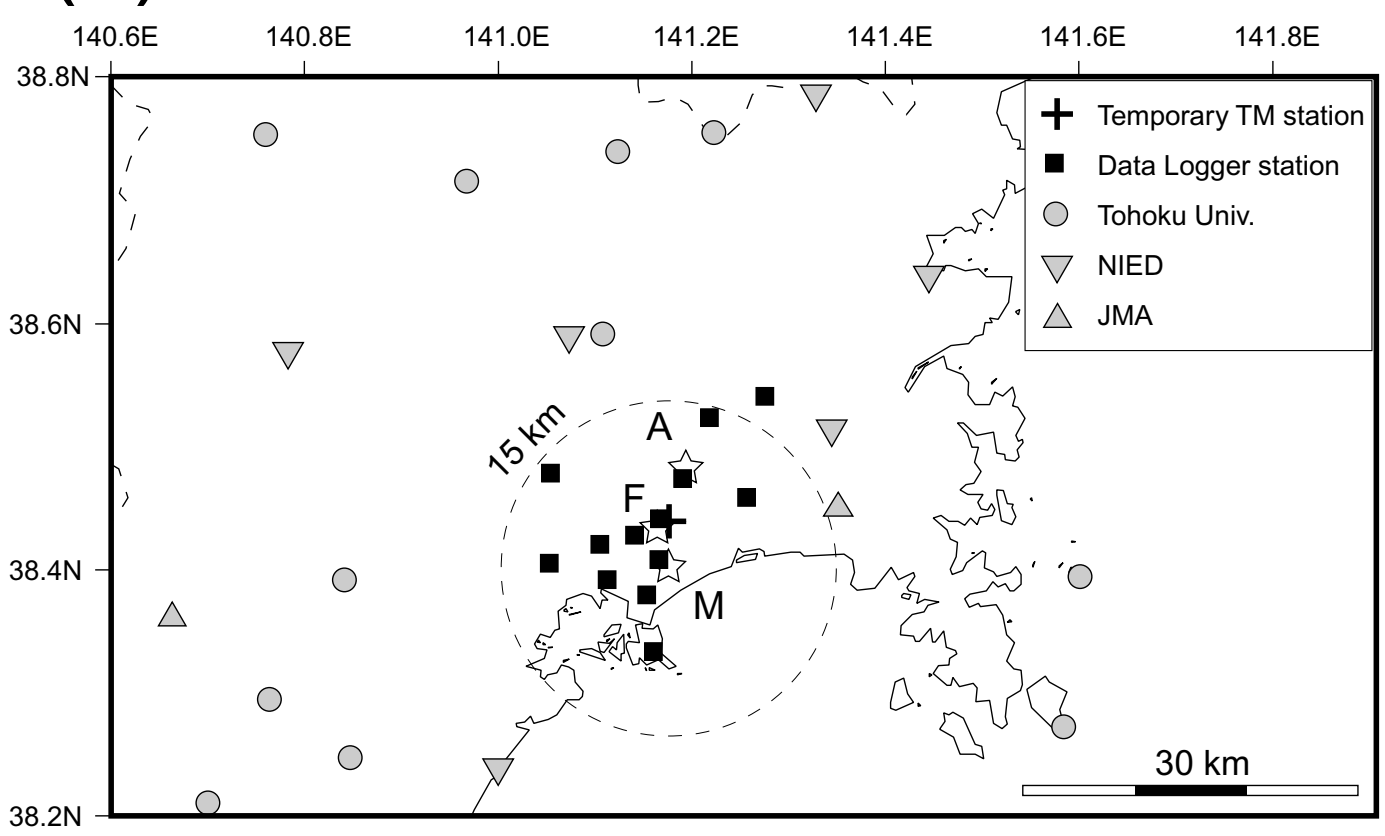

Fig. 1. (a) Map showing study area. Gray rectangle in the inserted map denotes the study area shown in (b). (b) Map showing observation stations and epicenters of July 26, 2003, northern Miyagi earthquake sequence. Solid squares and a cross denote locations of temporary data-logger stations and a satellite communication telemetry station, respectively. Gray circles, reverse triangles and triangles show locations of seismic stations of Tohoku University, National Research Institute for Earth Science and Disaster Prevention (NIED), and Japan Meteorological Agency (JMA), respectively. Stars F, M and A denote epicenters of the largest foreshock (M5.6), the main shock (M6.4) and the largest aftershock (M5.5), respectively.

Obtained hypocenters of aftershocks and standard deviations of their locations are shown by open circles and thin lines in Fig. 2, respectively. Only aftershocks whose standard deviations of hypocenters are less than $1 \mathrm{~km}$ are shown in this figure. Vertical cross sections of aftershocks are shown in Figs. 2(b), (c) and (d), and locations of the cross sections are shown by NS, $\mathrm{AA}^{\prime}$ and $\mathrm{BB}^{\prime}$ in Fig. 2(a). Only aftershocks in the northern part (north of $\mathrm{XX}^{\prime}$ in Fig. 2(a)) of the aftershock area are shown in Fig. 2(c), and only aftershocks in the southern part (south of XX' in Fig. 2(a)) of the aftershock area are also shown in Fig. 2(d). Hypocenter distribution of aftershocks presently determined delineates the fault plane of the present M6.4 earthquake sequence in the depth range of 3-12 km. It dips to the west at an angle of $\sim 50$ degree in 

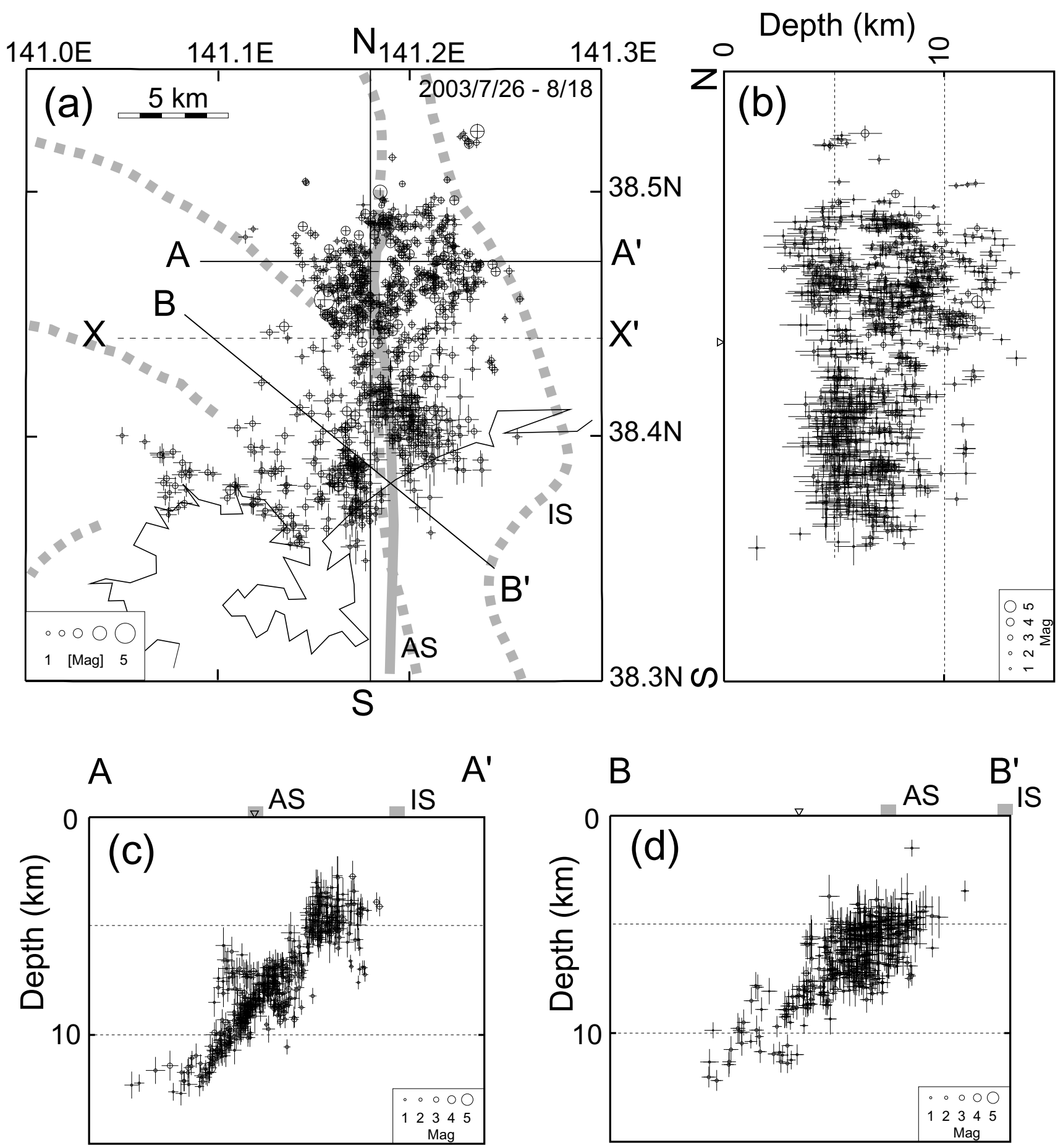

Fig. 2. Distribution of aftershocks determined by temporary observation data. Locations of aftershocks and standard deviations of them are shown by open circles and thin lines, respectively. Only aftershocks whose standard deviations of hypocenters are less than $1 \mathrm{~km}$ are shown in this figure. Thick gray line AS denotes Asahiyama flexure (Active Fault Research Group, 1991). Gray dashed line IS shows the location of Ishinomaki-wan fault (Nakamura, 1992). (a) Map view. (b) NS vertical cross section. (c) Vertical cross section along line $A^{\prime} A^{\prime}$ in (a). Aftershocks in the northern part (north of XX' in (a)) of the aftershock area are shown. (d) Vertical cross section along line BB' in (a). Aftershocks in the southern part (south of XX' in (a)) of the aftershock area are shown.

the northern part of the aftershock area and to the northwest at an angle of $\sim 40$ degree in the southern part. Line $X^{\prime}$ in Fig. 2(a) denotes the approximate boundary between these northern and southern part of the aftershock area.

Gray line (AS) in Fig. 2(a) denotes Asahiyama flexure (Active Fault Research Group, 1991). Gray dashed line (IS) shows Ishinomaki-wan fault, which was reactivated from normal faulting in Miocene to reverse faulting since late Pliocene (Nakamura, 1992). It dips to the west. Locations of these geological structures are also shown by gray lines on the top of the vertical cross sections. As shown in Fig. 2(c), the fault plane of the M6.4 event revealed from the aftershock distribution is probably located on the Ishinomaki-wan fault at depths from $3 \mathrm{~km}$ to $12 \mathrm{~km}$. The dip angle of this hypocen- 

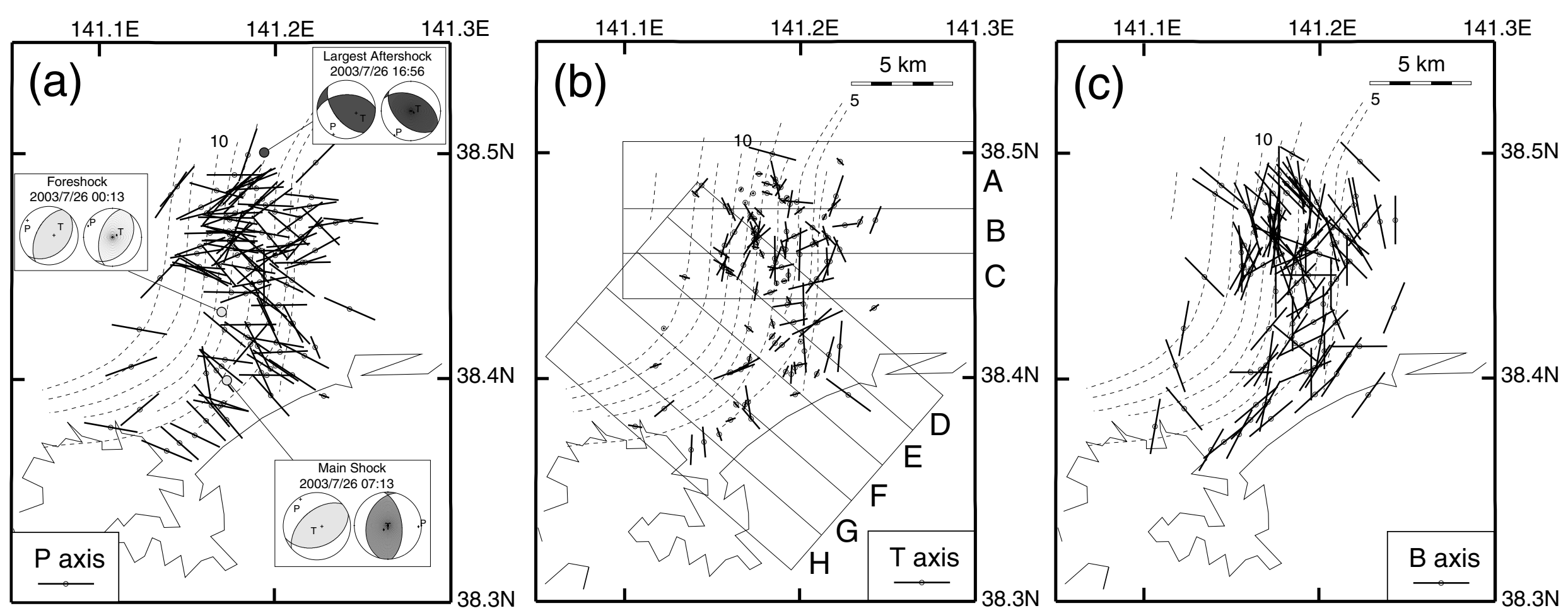

Fig. 3. Distributions of (a) $P$-, (b) $T$ - and (c) $B$-axes of focal mechanisms of aftershocks determined by $P$-wave initial motions. Dip angles of those axes are shown by lengths of thick lines. Dashed lines show iso-depth contours of the M6.4 fault plane. Focal mechanisms of the largest foreshock, the main shock and the largest aftershock (Okada et al., 2003) are shown in (a). Locations of vertical cross sections shown in Fig. 5 are shown by rectangles in 

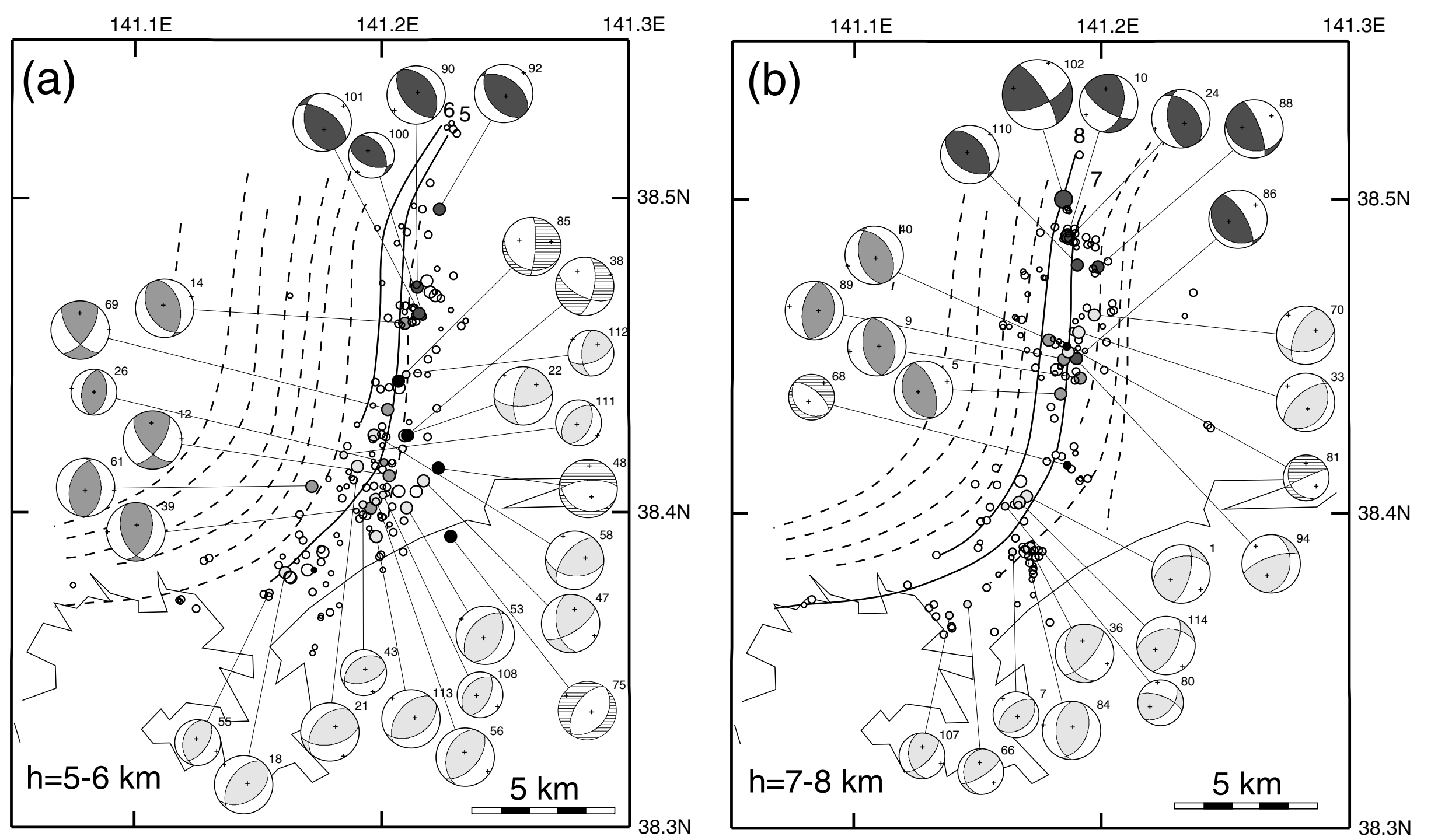

Fig. 4. Focal mechanisms of aftershocks determined by $P$-wave polarities. Gray colors in focal spheres denote three types of focal mechanisms (see text). Hatched focal mechanisms denote normal fault types or reverse fault types with directions of $P$-axes different from predominant NW-SE directions. Only focal mechanisms estimated by 20 or more $P$-wave polarities are shown in this figure. Numerals attached to individual events are earthquake number allocated to aftershocks in chronological order. Solid lines denote iso-depth contours corresponding to the depth range of each figure. Open circles show hypocenters of aftershocks in each depth range. (a) Focal mechanisms of aftershocks with focal depths of 5-6 km. (b) Focal mechanisms of aftershocks with focal depths of $7-8 \mathrm{~km}$. 

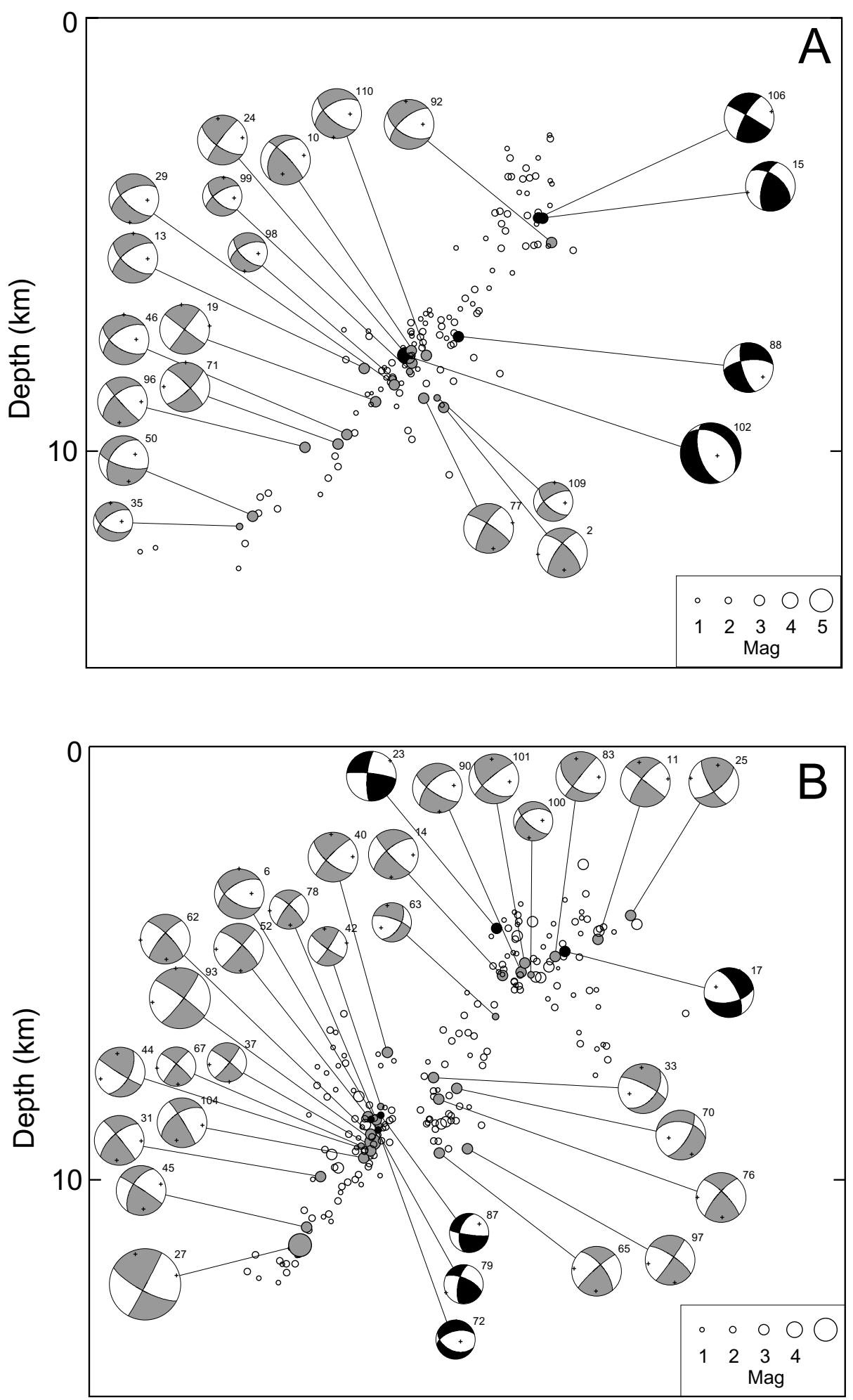

Fig. 5. Vertical cross sections of focal mechanisms of aftershocks determined by $P$-wave polarities. Locations of vertical cross sections A-H are shown by rectangles in Fig. 3(b). Focal mechanisms estimated by 20 or more $P$-wave polarities are shown in this figure. Numerals attached to individual events are earthquake number allocated to aftershocks in chronological order. Gray and black focal mechanisms denote those whose nodal plane is nearly parallel to the dip of the fault plane or not, respectively. Open circles show hypocenters of aftershocks in each rectangular region (Fig. 3(b)).

ter distribution of aftershocks decreases abruptly at a depth of $12 \mathrm{~km}$, the deepest portion, in the northern part of the aftershock area (Fig. 2(c)), suggesting the existence of a detachment fault of this M6.4 earthquake fault.

\section{Focal mechanisms of aftershocks}

Focal mechanisms and moment tensor solutions of the largest foreshock, the main shock and the largest aftershock were determined by Okada et al. (2003) and are shown in Fig. 3(a). Focal mechanisms determined by $P$-wave polarities are shown on the left and the moment tensor solutions 

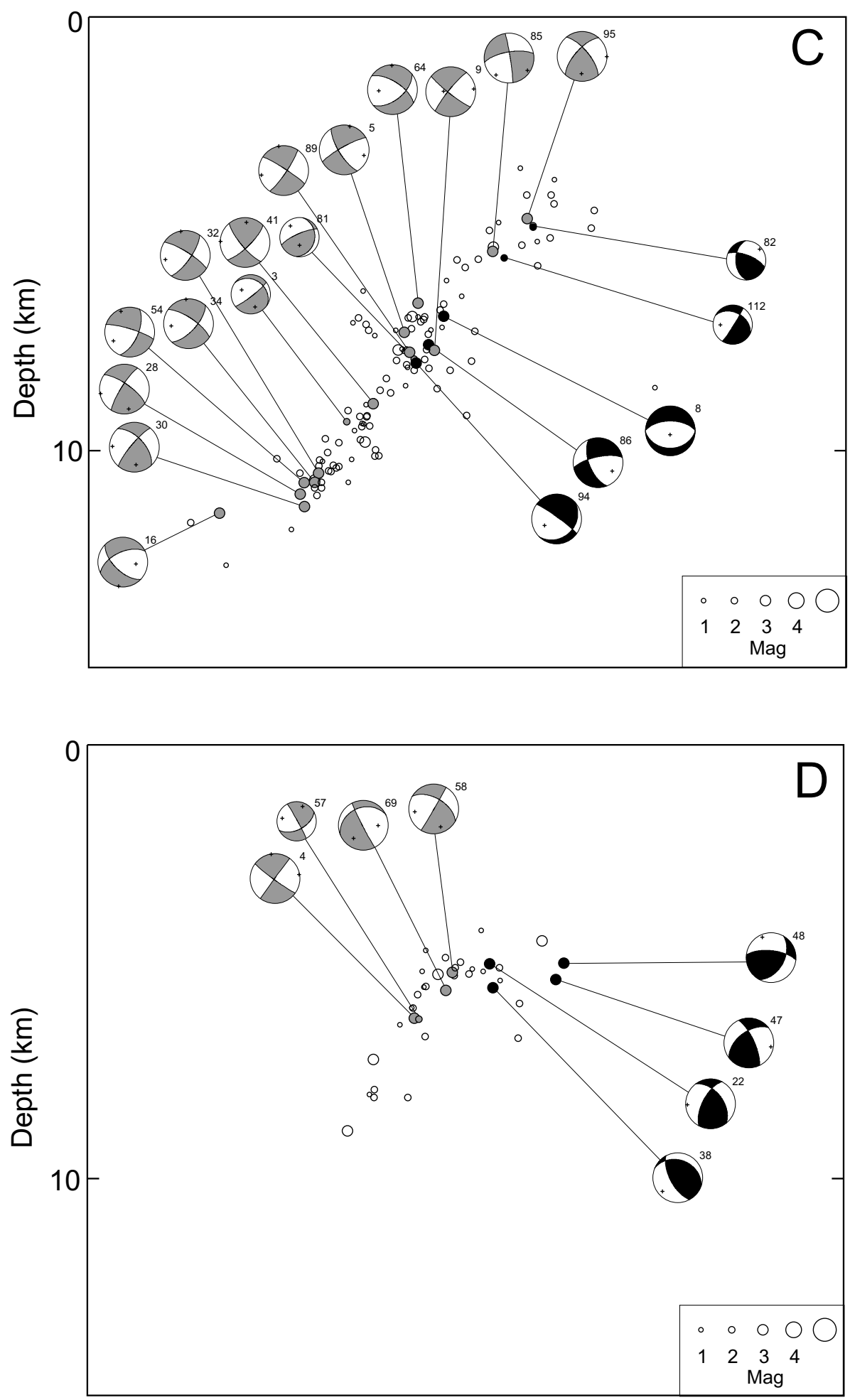

Fig. 5. (continued).

determined from waveform inversions are shown on the right of each of inserted panel in Fig. 3(a). All the events have reverse fault type focal mechanisms. There exists some difference in the direction of $P$-axis of the main shock between the focal mechanism estimated from $P$-wave polarities and that of the moment tensor solution.

Rupture process of the main shock was revealed by waveform inversions of nearby strong-motion seismograms and teleseismic broadband seismograms (e.g., Hikima and
Koketsu, 2003; Sekiguchi et al., 2003; Yagi et al., 2003). Yagi et al. (2003) showed that fault slip was initiated at a location in the southern part of the main shock fault plane, and the large amount of fault slip took place in the central part of the fault. The large coseismic slip in the central part is also obtained from GPS data analysis (Miura et al., 2003). Focal mechanism estimated from initial motions of $P$-waves perhaps reflects the initial rupture process, whereas moment tensor solution reflects the main rupture process. The directions 

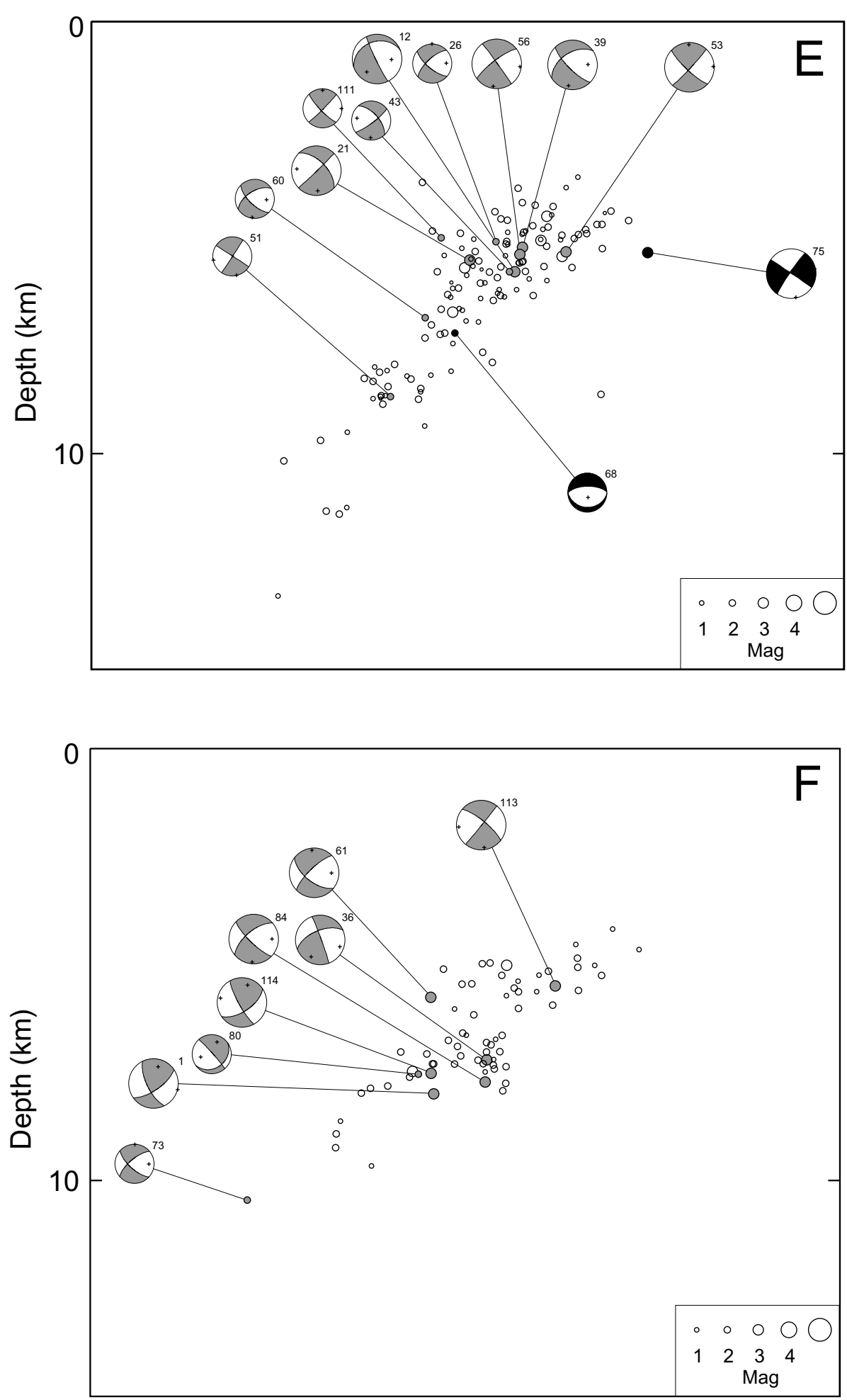

Fig. 5. (continued).

of $P$-axes of the focal mechanism solution and the moment tensor solution are consistent with the curved fault plane determined from distribution of aftershocks, whose iso-depth contours are shown by dashed lines in Fig. 3.

Many focal mechanisms of aftershocks could be determined by using $P$-wave polarities observed at the temporary stations and nearby permanent stations. Four best fitting focal mechanisms were estimated by 20 or more $P$-wave polarities (Horiuchi et al., 1972). Only events with small discrep- ancies between those four focal mechanism solutions were adopted in this study. Accuracy of $P-, T$-axes is estimated to be about 10 degrees. Distributions of $P-, T$ - and $B$-axes of focal mechanisms of aftershocks are shown by thick lines in Figs. 3(a), (b) and (c), respectively. Lengths of thick lines denote dip angles of those axes. Directions of $P$-axes of aftershocks varies with their epicenter locations. $P$-axes of aftershocks in the southern part of the aftershock area have NW-SE directions. In the central part of the aftershock area, 

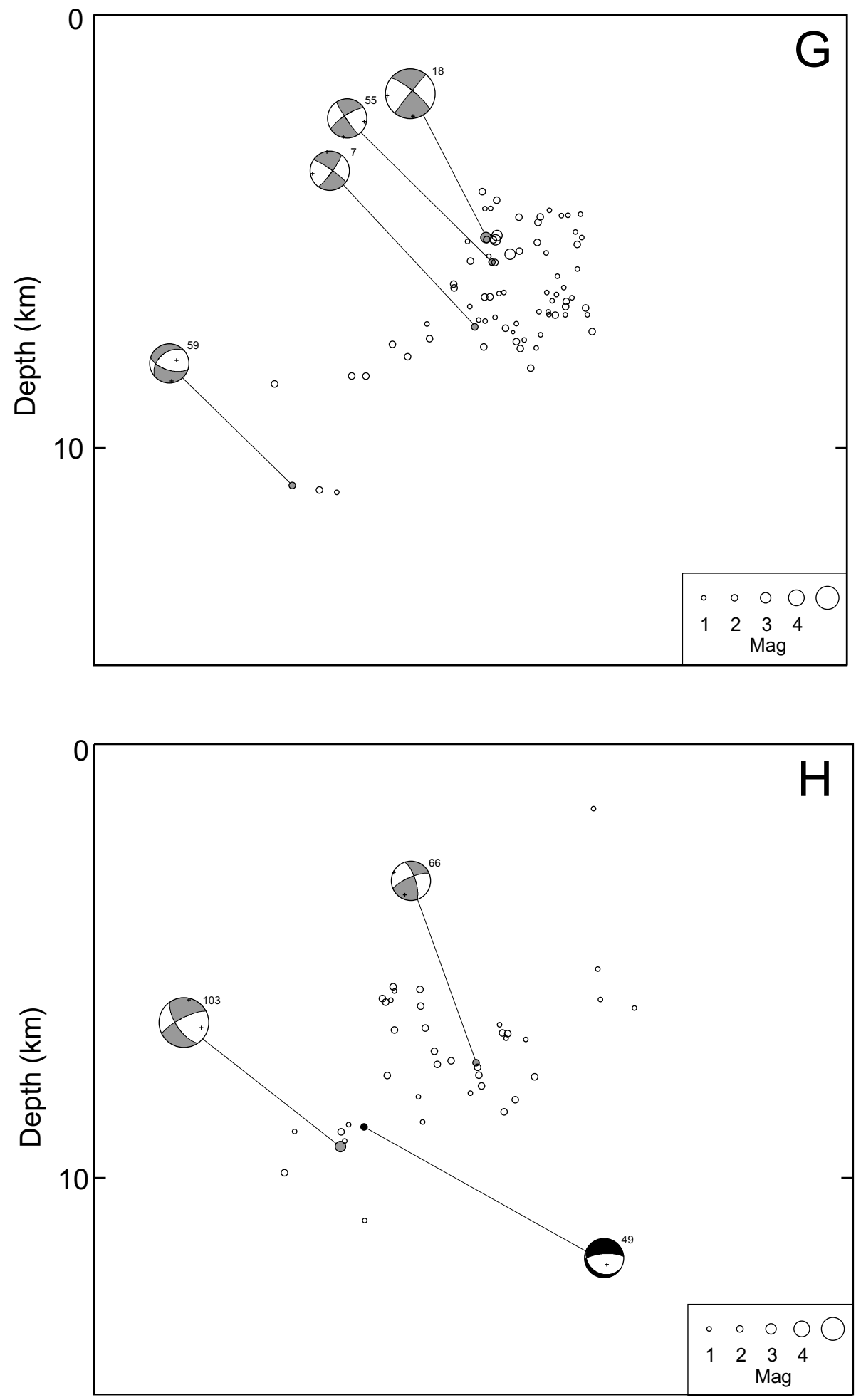

Fig. 5. (continued).

$P$-axes of aftershocks are east-west. Directions of $P$-axes of aftershocks in the northernmost part of the aftershock area are NE-SW. $P$-axes of aftershocks for the three areas are similar to those of the largest foreshock, the main shock and the largest aftershock (Okada et al., 2003), respectively, as mentioned above.

$B$-axes of aftershocks are aligned mostly along the curved fault plane shown by iso-depth contours for the southern and central part of the aftershock area. In the northernmost part of the aftershock area, most of $B$-axes have NW-SE directions. $B$-axes of aftershocks in the westernmost part of the aftershock area are nearly perpendicular to the strike of the curved fault plane.

Distributions of focal mechanisms for aftershocks in the depth ranges of 5-6 km and 7-8 km are shown in Figs. 4(a) and (b), respectively. Open circles denote epicenters of aftershocks that occurred in each depth range. Focal mechanism of reverse fault type is predominant in this earthquake 

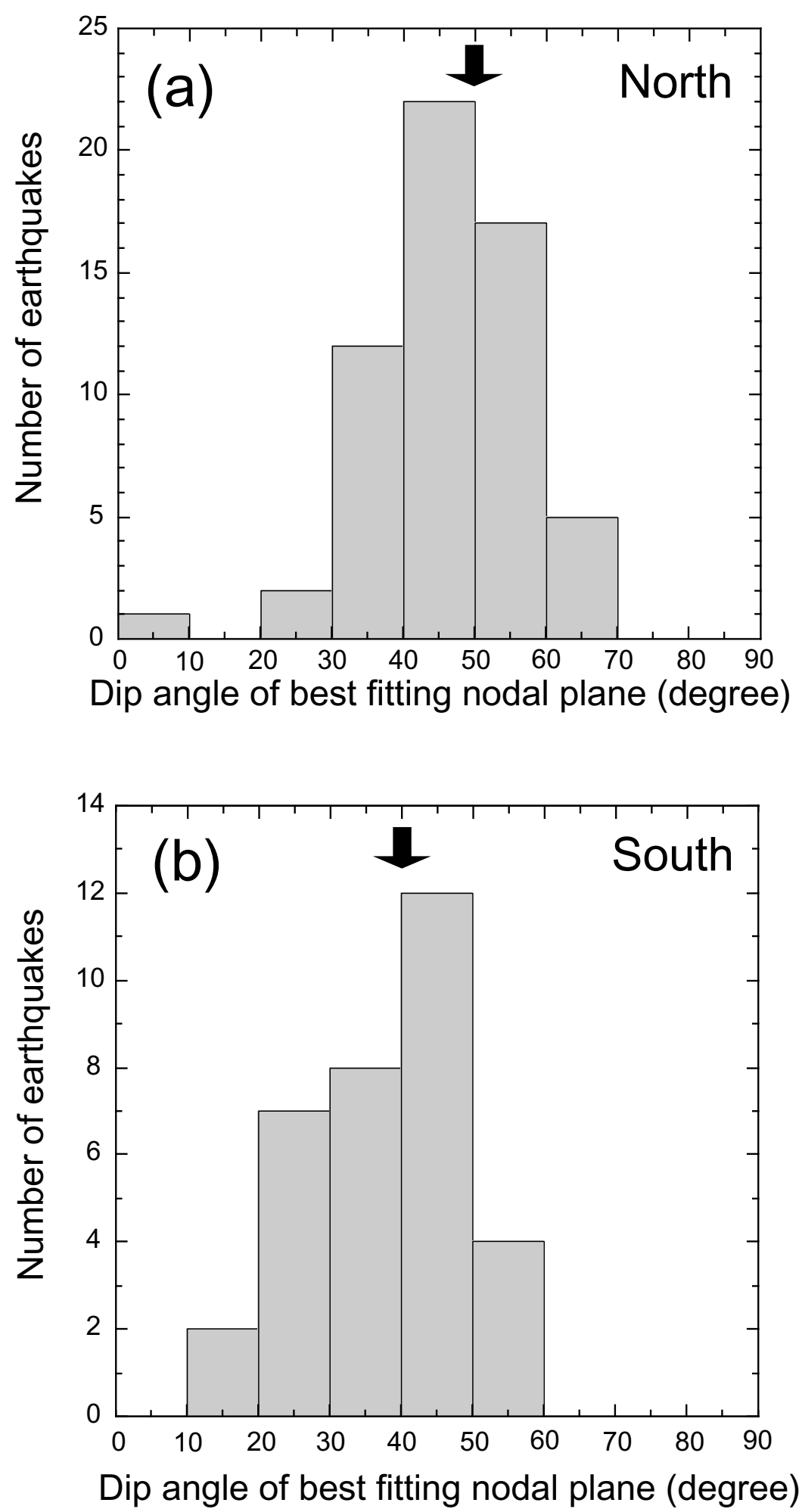

Fig. 6. Dip angle distribution of fault planes of aftershocks. Numbers of aftershocks in the northern part of the aftershock area (shown in Fig. 2(c)) are shown in (a), and those in the southern part (shown in Fig. 2(d)) in (b), respectively. Aftershocks with normal fault type focal mechanisms (shown by black focal mechanisms in Fig. 5) are excluded. A dip angle of the main fault revealed from aftershock distribution in the northern and southern part is roughly estimated and is shown by a thick arrow in (a) and (b), respectively.

sequence including the largest foreshock (M5.6), the main shock (M6.4) and the largest aftershock (M5.5) (as shown in Fig. 3(a)). Based on directions of $P$-axis of focal mechanisms, we classified focal mechanisms of aftershocks into three groups. Light gray, gray and dark gray focal spheres denote focal mechanisms whose $P$-axes are NW-SE, east- west and SW-NE directions, respectively. Aftershocks with $P$-axis of NW-SE direction occurred mainly in the southern part of the aftershock area where the M5.6 foreshock and the main shock ruptures initiated. Strikes of the iso-depth contours are NE-SW, which is almost perpendicular to the directions of $P$-axis for most of aftershocks in this region. 
Many aftershocks with $P$-axes of east-west direction took place in the central part of the aftershock area where large amount of fault slips by the main shock were estimated by waveform inversions (Yagi et al., 2003). Many aftershocks in the northernmost part of the aftershock area have the same focal mechanisms as that of the M5.5 largest aftershock.

There exist a few aftershocks with different focal mechanisms from those three groups. They are shown by hatched focal spheres in Fig. 4. These focal mechanisms are normal fault types or reverse fault types with directions of $P$-axes different from predominant NW-SE directions. Those aftershocks occurred very close to the bend of the curved fault plane of the M6.4 earthquake revealed by the iso-depth contours (events 38, 68, 85 in Fig. 4), or outside of the fault plane (event 48, 75 in Fig. 4).

Vertical cross sections of focal mechanisms of aftershocks are shown in Figs. 5(a)-(h). Locations of these vertical cross sections are shown by rectangles in Fig. 3(b). Focal mechanisms of aftershocks are projected on a wall-side hemisphere. In order to avoid duplication of projections, focal mechanisms of aftershocks in region A, B and C (shown in Fig. 3(b)) are not projected in Figs. 5(d)-(h). Gray or black focal mechanism denotes the cases in which its nodal plane is nearly parallel (within $\sim 20$ degrees) to the dip of the main fault plane or not, respectively. Most of aftershocks have westward dipping nodal planes nearly parallel to the dip of the M6.4 curved fault plane. Aftershocks 2, 13, 77, and 109 (in Fig. 5(a)), 40, 65, and 97 (in Fig. 5(b)), 111 (in Fig. 5(e)), 61 (in Fig. 5(f)) occurred out of the westward dipping main fault and are also a reverse fault type. Aftershocks occurring in northern part of the aftershock area (shown by black focal mechanisms in Figs. 5(d) and (e)), whose nodal planes are not parallel to the dip of the M6.4 fault plane, took place just below the aftershocks of reverse fault types shown by gray focal mechanisms.

Since aftershock activity in the detachment fault region is very low, only one focal mechanism of event 16 could be determined (Fig. 5(c)). Dip of the westward dipping fault plane is very small and seems to be similar with that of the detachment fault, suggested by hypocenter distribution of aftershocks (shown in Fig. 2(c)).

\section{Discussion}

The estimated fault plane of the M6.4 event is not a simple plane but a curved surface depicted by iso-depth contours shown in Fig. 3. The dashed line IS shown in Fig. 2(a) is the surface trace of the Ishinomaki-wan fault, which was reactivated from normal faulting in Miocene to reverse faulting since late Pliocene. Fault reactivation from Miocene normal faulting to later reverse faulting in this region was revealed by Nakamura (1992). The upward extension of the depth distribution of aftershocks coincides with the surface trace of the Ishinomaki-wan fault as shown on the top of Figs. 2(c) and (d).

The shape of the fault plane in the southern part of the aftershock area seems to be consistent with the bending of the Ishinomaki-wan fault trace at the southern offshore region. In the northern part of the aftershock area, $P$-axis of the aftershock and that of the largest aftershock (Fig. 3(a)) are NESW direction, almost perpendicular to the surface trace of the northern part of the Ishinomaki-wan fault (Fig. 2(a)). On the contrary, the surface trace of the Ishinomaki-wan fault seems to be inconsistent with the iso-depth contours of the main fault there. There is room for further investigation about this inconsistency between the surface trace of the Ishinomakiwan fault and the iso-depth contours of the main fault.

Frequency of dip angles of the fault planes of aftershocks in northern and southern part of the aftershock area (shown in Fig. 2(c) and (d)) are shown in Figs. 6(a) and (b), respectively. Aftershocks with normal fault type focal mechanisms (shown by black mechanisms in Fig. 5) are excluded in this figure. A dip angle of the main fault revealed from aftershock distribution in the northern and southern part (shown in Figs. 2(c) and (d)) is roughly estimated as to be 50 and 40 degrees, and is shown by a thick arrow in Figs. 6(a) and (b), respectively. Dip angles of the fault planes of aftershocks in the northern part seem to be steeper than those in the southern part.

Yamamoto (2003) investigated gravity anomaly distribution in this region and pointed out that a zone of abrupt gravity change dipping to the west is located almost parallel with the surface trace of the Ishinomaki-wan fault. It is likely that the rupture of M6.4 earthquake took place along the Ishinomaki-wan fault at depths of 3-12 km.

The dip angle of the fault is as steep as about 50 degree, though the present event is reverse fault type. This seems to be consistent with the reactivation of the normal fault of the present event.

\section{Conclusions}

Fault configuration of 2003 M6.4 northern Miyagi earthquake and distribution of focal mechanisms of aftershocks were revealed from data observed at temporary stations deployed densely right above the focal area after the occurrence of the M6.4 event.

(1) Estimated fault plane is not a simple plane but a curved surface. The northern part of the fault plane dips to the west at an angle of $\sim 50$ degree, and the southern part to the northwest at $\sim 40$ degree.

(2) Predominant focal mechanisms of aftershocks are reverse fault types. Aftershocks with $P$-axes of NW-SE direction mainly occurred in the southern part of the aftershock area. Aftershocks with $P$-axes of east-west direction took place in the central part of the aftershock area, and those with $P$-axes of NE-SW directions in the northernmost part of the aftershock area.

(3) A few aftershocks with normal fault types occurred close to the bend of the curved fault plane or outside of the fault plane.

(4) Nodal planes of aftershocks of reverse fault types are nearly parallel to the M6.4 fault plane both in the central and southern parts of the aftershock area.

(5) The rupture of the M6.4 earthquake took place along the Ishinomaki-wan fault at depths of 3-12 km.

Acknowledgments. We acknowledge the helpful comments and reviews by Björn Lund and Shozo Matsumura. We would like to thank the members of Research Center for Prediction of Earthquakes and Volcanic Eruptions, Graduate School of Science, Tohoku University. We are grateful to the staff of the National Research Institute for Earth Science and Disaster Prevention (NIED), 
and the Japan Meteorological Agency (JMA) for allowing us to use data observed by their seismic stations. This research was partly supported by a grant from the Ministry of Education, Culture, Sports, Sciences and Technology (MEXT) (No. 15800009).

\section{References}

Active Fault Research Group, Active Faults in Japan: sheet maps and inventories (Revised edition), 437 pp., University of Tokyo Press, Tokyo, 1991 (in Japanese).

Hasegawa, A., N. Umino, and A. Takagi, Double-planed structure of the deep seismic zone in the northeastern Japan arc, Tectonophysics, 47, 4358, 1978 .

Hikima, K. and K. Koketsu, July 26, 2003 Miyagi-ken Hokubu earthquake: Source processes of fore-, main and largest after-shocks, Programme and Abstracts the Seismological Society of Japan 2003, Fall Meeting, A085, 2003.

Horiuchi, S., K. Emura, and T. Hirasawa, Reliability of pressure and tension axes determined by initial motions of $P$-wave from deep earthquakes in and near japan: The use of J.M.A. network, J. Seism. Soc. Japan (Zisin) 25, 92-104, 1972 (in Japanese with English abstract).

Miura, S., Y. Suwa, T. Sato, K. Tachibana, and A. Hasegawa, Slip distribution of the 2003 northern Miyagi earthquake (M6.4) as deduced by geodetic inversion, Earth Planets Space, 2003 (submitted).

Nakamura, K., Inversion tectonics and its structural expression, J. Tectonic Res. Group Japan, 38, 3-45, 1992 (in Japanese with English abstract).

Okada, T., N. Umino, and A. Hasegawa, Rupture process of Jul. 262003 northern Miyagi earthquake sequence, NE Japan, estimated from doubledifference hypocenter locations, Earth Planets Space, 55, this issue, 741-
750,2003

Sekiguchi, H., S. Aoi, R. Honda, T. Kunugi, S. Senna, and H. Fujuwara, Ground motion and rupture process of the 26 July 2003 northern Miyag earthquake obtained from strong motion data of K-NET and KiK-net Programme and Abstracts the Seismological Society of Japan 2003, Fall Meeting, A084, 2003.

Umino, N., T. Okada, J. Nakajima, S. Hori, T. Kono, T. Nakayama, N. Uchida, J. Shimizu, J. Suganomata, G. Shantha, K. Nida, Y. Yabe, K. Sakoda, N. Sato, M. Ito, A. Hasegawa, Y. Asano, A. Hasemi, T. Demachi, and Y. Yajima, Hypocenter and focal mechanism distributions of aftershocks of July 262003 M6.2 northern Miyagi earthquake revealed by temporary observations, J. Seism. Soc. Japan (Zisin), 2003 (in Japanese with English abstract) (submitted).

Waldhauser, F. and W. L. Ellsworth, A double-difference earthquake location algorithm: Method and application to the northern Hayward fault California, Bull. Seism. Soc. Am., 90, 1353-1368, 2001.

Yagi, Y., Y. Ito, Y. Asano, and S. Sekine, Fore-shock, Main-shock and the largest aftershock associated with the July 262003 Miyagi-ken-hokubu, Japan, earthquake, Programme and Abstracts the Seismological Society of Japan 2003, Fall Meeting, A086, 2003.

Yamamoto, A., Gravity anomaly in and around the epicentral area of the 2003 northern Miyagi earthquakes (2003/7/26), northeastern Japan, Programme and Abstracts the Seismological Society of Japan 2003, Fall Meeting, P192, 2003.

N. Umino (e-mail: umino@aob.geophys.tohoku.ac.jp), T. Okada, J. Nakajima, S. Hori, T. Kono, T. Nakayama, N. Uchida, J. Shimizu, J. Suganomata, S. S. N. Gamage, A. Hasegawa, and Y. Asano 